\title{
Data Work in Health Care: The Case of Medical Secretaries
}

\author{
Casper KNUDSEN ${ }^{\text {a }}$, and Pernille Scholdan BERTELSEN ${ }^{\mathrm{a}}$ \\ ${ }^{a}$ Aalborg University, Department of Planning
}

\begin{abstract}
This paper investigates the often neglected area of data work by medical secretaries, specifically in the context of hospitals in Denmark. Since the 1930s medical secretaries have played a steadily more central role in meeting the growing need for health data. With electronic health records (EHRs) and promises of data automation, the profession has been put at risk of redundancy. While there is a considerable base of research on the datafication of health care, the data work emerging from datafication remains undescribed. Hence, we are conducting a sociotechnical study of clinical-administrative data work in contemporary Danish public hospitals. In this paper we present early insights of this research, indicating the vital role of medical secretaries' data work in securing clinical information at the point of care.
\end{abstract}

Keywords. Data work, EHR, electronic health record, administrative work, hospitals, socio-technical research, medical secretaries

\section{Introduction}

Since the 1800s the interconnected trends of standardization and scientific medicine have increased the need for nonmedical administrative skills and human resources in hospitals $[1,2]$. Along with the introduction and explosive development and scope of standardized health records, new professions have emerged to meet the demand for more and better data in health care [1], [3]. The rise of data as the new "oil" of the information economy [4], along with widespread digitalization, has become evident in health care and in the broader society in many countries [5,6] - including the strategies of the Danish government [7].

Data, including health data, is not simply pumped out of the ground to flow frictionless through organizations, as the oil metaphor might suggest. As the emerging field of critical data studies argue, data is entangled in the contexts of its production and use; it requires hermeneutic judgement and situated work [8]. Thus, the concept of "raw data" is an oxymoron [9]. Large-scale data is a product of the work of many people and professions [10], creating new professions [3] and leading older professions to take on new tasks [10]. In this study we apply a broad definition of data work, which we refer to as "any activity related to creating, collecting, managing, curating, analyzing, interpreting, and communicating data whether these are facts, numbers, letters, or symbols that describe an object, idea, condition, situation, or other factors" [3].

Especially since the $1950 \mathrm{~s}$, with the increasing rate of progress in scientific medicine, medical secretaries have been at the center of data work at Danish hospitals and instrumental to meeting the increasing need for situated data work, data quality, and data management at the ward level. 
Fewer studies have focused on understanding the work of medical secretaries than have focused on the work of physicians or nurses. This could be due to the lower number of medical secretaries, but it may also be because medical secretaries and other administrative workers are more likely to be invisible in the eyes of managers and researchers [11-13]. The terms used for clerical and administrative workers in hospitals vary by country $[1,14,15]$, also making research difficult to compare.

Studies of medical secretaries in the context of Danish public hospitals argue that the profession carries out a wide range of patient-oriented and health-administrative tasks and support to clinicians' work, stretching far beyond simply "being secretary to the physician" and transcribing medical notes $[16,17]$. Some studies argue that medical secretaries are central to the work in and around patient records [18]. Studies highlight medical secretaries acting as "organisational glue' or [the] connecting thread between other professional groups at the hospital" [19] — a quality partly attributed to the decentralized distribution of medical secretaries at ward level in Danish hospitals, which affords deep domain knowledge of the medical specialty they work in. Other studies argue that medical secretaries do not solely operate in administration; that they are positioned at the “'intersection' of formally separate but practically enmeshed practices, namely administrative and clinical work" [20]. Thus, they support and are a direct part of clinical work, making professional judgements informed by a unique combination of knowledge about medicine, administration, and care pathways [20,21]. The work of medical secretaries, however, as that of many other clerical workers, often gets relegated to the background $[16,17,22]$, regarded as automatable, routine work of little value [23], [24]. In Denmark, new electronic health record (EHR) systems have been partly financed through the redundancy of medical secretaries. This occurred most recently between 2017 and 2018, with the implementation of the EPIC EHR system in two Danish regions.

This paper presents early insights from a 2021 study of medical secretaries' data work in Danish hospitals. Their data work is an interesting case for understanding the changing role of data work in digital health care. The study is part of a larger research project ${ }^{1}$ investigating new knowledge and skills required to work with data in an increasingly digitalized health care sector and how this new kind of data work impacts professions.

\section{Methods}

This study's empirical data derive from participant observations (eight days) and in situ interviews in four hospital departments at in- and outpatient clinics (two in cardiology, one in neurosurgery, and one in diagnostic imaging) using two EHR systems in three different hospitals in two regions in Denmark. Also, two interviews were conducted with representatives of HK-DL, the union of medical secretaries, at the national $(n=1)$ and regional level $(n=4)$.

Participant observations were carried out by job shadowing medical secretaries in different functions, spending two days at each department. The purpose of engaging in multisite observation was to observe their data work across different technological and organizational contexts to gain a broad understanding of their work and to identify relevant emerging categories during the early stages of a sociotechnical study.

${ }^{1}$ The project is funded by the Independent Research Fund Denmark (grant 0132-00200B: "Making Data Work Visible"). See https://projects.au.dk/datawork. 
During observation, extensive handwritten notes were 'jotted down' [25] and subsequently typed. Collected data also comprise a range of relevant documents identified during observation. Field notes and documents have been coded and categorized. While the process of analysis will continue as the fieldwork and research continues, the following example represents one emerging category present in the data.

\section{Results and analysis}

A significant part of medical secretaries' data work takes place within and in relation to the EHR ensuring that EHR data is complete, updated, and correctly coded. Correct and updated data is vital in relation to clinical work, patient safety, and the financial management of the department, emphasizing the importance of the data work performed by medical secretaries in making sure that EHR data is "trimmed" [18]. However, a maybe less obvious set of tasks that our study shows is undertaken by medical secretaries involves instances when the technical infrastructure does not allow for data to "flow," requiring data to be moved manually through the system to enable access to the right data at the point of care. These cases are the focus of this article.

Weak interoperability between hospitals' digital health care systems, municipalities and general practitioners (GP) creates a need for manually supported processes to be performed by medical secretaries. In the case of a cardiological department, to initiate the clinical decision-process based on a referral, an ECG must be included in the referral from the GP. However, one medical secretary in this study explained how this is often not the case. The seemingly simple problem of obtaining an already existent ECG from a GP triggers a wide range of tasks: creating a correspondence note, follow-ups, telephone calls with the GP, receiving faxes of the ECG (which often cannot be sent digitally between the GP and the hospital), scanning the document and attaching it to the patient's EHR, finally enabling the further processing of the referral. Similar tasks are required when weak interoperability between health care institutions and IT systems means that image data from the radiology department must be transferred to DVDs and forwarded to outside specialist clinics or are received at the hospital on DVDs. Both are examples of how the data work of medical secretaries supports clinical care by providing needed clinical information at the point of care-information that would otherwise be unavailable in clinical work due to weak interoperability.

Our study suggests that, in addition to bridging the gaps in data journeys, medical secretaries often play active roles in supporting the ongoing digitalization of department workflows to close gaps in data journeys. In one department, a medical secretary had initiated the digitalization of the patient-surgeon preoperation conversation, which simplified the process for both the clinical and administrative context. In another department, the head medical secretary persuaded clinic management to take advantage of an EHR update to fully abandon paper-based workflows. In a third department, which still maintained a substantial number of paper-based processes (e.g., in relation to the visitation process), medical secretaries maintained two parallel data flows: one digital and one paper-based. The medical secretaries in the department presented as a form of collegial care - a way to help the clinical staff "make things run smoothly," although it created a considerable amount of work (e.g., printing referral data, preparing for clinical personnel, and entering visitation data back into the EHR) for the medical secretaries. One of the medical secretaries stated that the clinical personnel "could probably learn how to do it [the digital workflow], but we have prioritized speed," adding that "maybe 
we are wrapping them in cotton wool.", suggesting that medical secretaries play a significant role in the digitalization process at the departmental level.

\section{Discussion and Conclusion}

In the opening of this article, we pointed to the problematic view that sees data as something that flows frictionlessly through organizations. Based on insights from our fieldwork, we show how medical secretaries' data work is integral to enabling the movement of data and the ongoing development of procedures and workflows for data work.

While continuous threats of being "automated away" remain, medical secretaries in Danish public hospitals have been able to adapt and remain essential despite technological and organizational changes. They have evolved from "physician's secretary" to health administrative coordinators in a health sector that aims to become data-informed, if not data-driven.

As shown in multiple studies [26, 27], both technical and socio-technical issues often arise when EHR systems and workflows collide, leading to unintended consequences and errors; the new system fixes one set of problems only to create others. We argue that medical secretaries in Danish hospitals play a vital role in mitigating both technical and sociotechnical issues.

Several studies emphasize that health-administrative personnel play a vital role in creating and sustaining cohesion in hospitals, such as health information managers in Australia [1] and secretaries in Norway [14] and in Denmark [16, 17, 19, 20]. While clinical work is documented through, for example, DRG codes, the administrative tasks (e.g., follow-ups and telephone queuing to gather missing data) taken to bridge gaps in data journeys remain informal. Thus, medical secretaries' data work runs the risk of becoming invisible when designing and implementing EHRs and other technological and organizational changes. This calls for further investigation and illumination of the data work of medical secretaries.

\section{References}

[1] K. M. Robinson, "The Dynamics of Health Information Management in Australia: The Emergence and Shaping of a Profession", 2017.

[2] M. Berg, Rationalizing Medical Work. Cambridge, Mass. [u.a.]: MIT Press, 1997.

[3] C. Bossen et al, "Data work in healthcare: An Introduction," Health Informatics Journal, vol. 25, (3), pp. 465-474, 2019. Available: https://journals.sagepub.com/doi/full/10.1177/1460458219864730. DOI: $10.1177 / 1460458219864730$.

[4] K. van Es and M. T. Schäfer, The Datafied Society. Studying Culture through Data. Amsterdam University Press, 2017.

[5] R. S. Evans, "Electronic Health Records: Then, Now, and in the Future," Yearbook of Medical Informatics, vol. 25, (S 01), pp. S48-S61, 2016. Available: http://dx.doi.org/10.15265/IYS-2016-s006. DOI: 10.15265/IYS-2016-s006.

[6] L. B. Madsen, Data-Driven Healthcare: How Analytics and BI are Transforming the Industry. John Wiley and Sons, 2014.

[7] Sundheds- og ældreministeriet. Sundhed i fremtiden. Ansvarlig brug af data. Sundheds- og ældreministeriet 2018..

[8] J. Bates, Y. Lin and P. Goodale, "Data journeys: Capturing the socio-material constitution of data objects and flows," Big Data \& Society, vol. 3, (2), pp. 205395171665450, 2016. Available: https://journals.sagepub.com/doi/full/10.1177/2053951716654502. DOI: 10.1177/2053951716654502. 
[9] L. Gitelman, Raw Data is an Oxymoron. MIT Press, 2013.

[10] N. H. Møller et al, "Who does the work of data?" Interactions, vol. 27, (3), pp. 52-55, 2020.

[11] M. Wichroski, "The Secretary: Invisible Labor in the Workworld of Women," Human Organization, vol. 53, (1), pp. 33-41, 1994. Available: https://www.jstor.org/stable/44126557. DOI: 10.17730/humo.53.1.a1205g53j7334631.

[12] C. Truss et al, "Still in the ghetto? Experiences of secretarial work in the 21st Century," Gender, Work, and Organization, vol. 20, (4), pp. 349-363, 2013. Available: http://www.fachportalpaedagogik.de/fis_bildung/suche/fis_set.html?FId=1009017. DOI: 10.1111/j.1468-0432.2012.00587.x.

[13] N. Møller, "The future of clerical work is precarious," Interactions (New York, N.Y.), vol. 25, pp. 75-77, Jun 27,. 2018.

[14] E. Håland and L. Melby, "Coding for quality? Accountability work in standardised cancer patient pathways (CPPs)," Health (London, England : 1997), pp. 13634593211013882, 2021. Available: https://www.ncbi.nlm.nih.gov/pubmed/33926302. DOI: 10.1177/13634593211013882.

[15] C. Bossen, Y. Chen and K. H. Pine, "The emergence of new data work occupations in healthcare: The case of medical scribes," International Journal of Medical Informatics (Shannon, Ireland), vol. 123, pp. 76-83, 2019. Available: https://dx.doi.org/10.1016/j.ijmedinf.2019.01.001. DOI: 10.1016/j.ijmedinf.2019.01.001.

[16] P. Bertelsen, Hvad Laver Lagesekretcrerne, Når De Ikke Er Sekretcrer for Lagerne? 2005.

[17] P. Bertelsen and P. Bertelsen, "Vil elektroniske patientjournaler overflødiggøre lægesekretærer på de danske sygehuse?" Tidsskrift for Arbejdsliv, vol. 9, (3), 2007.

[18] C. Bossen, L. G. Jensen and F. W. Udsen, "Boundary-object trimming: On the invisibility of medical secretaries' care of records in healthcare infrastructures," Computer Supported Cooperative Work $(C S C W)$, vol. 23, (1), pp. 75-110, 2014.

[19] P. Bertelsen and C. Nøhr, "The work practice of medical secretaries and the implementation of electronic health records in Denmark." Health Information Management Journal, vol. 34, (4), 2005.

[20] N. L. Holten Møller and S. Vikkelsø, "The clinical work of secretaries: Exploring the intersection of administrative and clinical work in the diagnosing process," in From Research to Practice in the Design of Cooperative Systems: Results and Open Challenges Anonymous London: Springer London, 2012, pp. 33-47.

[21] N. Holten Moller and P. Bjørn, "Layers in Sorting Practices: Sorting out Patients with Potential Cancer," Comput Supported Coop Work, vol. 20, (3), pp. 123-153, 2011. Available: https://search.proquest.com/docview/2258139642. DOI: 10.1007/s10606-011-9133-3.

[22] S. Star and A. Strauss, "Layers of Silence, Arenas of Voice: The Ecology of Visible and Invisible Work," Computer Supported Cooperative Work (CSCW), vol. 8, (1), pp. 9-30, 1999. Available: https://search.proquest.com/docview/2259969789. DOI: 10.1023/A:1008651105359.

[23] L. Suchman, "Making work visible," Commun ACM, vol. 38, (9), pp. 56-64, 1995.

[24] L. Suchman, "Making a case: knowledge and routine work in document production." 2000.

[25] H. Bernard, "Research Methods in Anthropology: Qualitative and Quantitative Approaches," 2011.

[26] J. S. Ash, M. Berg and E. Coiera, "Some Unintended Consequences of Information Technology in Health Care: The Nature of Patient Care Information System-related Errors," Journal of the American Medical Informatics Association, vol. 11, (2), pp. 104-112, 2004. Available: https://doi.org/10.1197/jamia.M1471. DOI: $10.1197 /$ jamia.M1471.

[27] S. Vanderhook and J. Abraham, "Unintended Consequences of EHR Systems: A Narrative Review," Proceedings of the International Symposium of Human Factors and Ergonomics in Healthcare, vol. 6, (1), pp. 218-225, 2017. Available: https://journals.sagepub.com/doi/full/10.1177/2327857917061048. DOI: $10.1177 / 2327857917061048$. 